\title{
COVID-19 susceptibility: potential of ACE2 polymorphisms
}

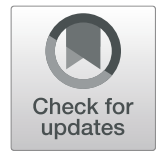

Mayank Chaudhary (1)

\begin{abstract}
Background: Angiotensin-converting enzyme 2 (ACE2) is a metallopeptidase that primarily functions as a negative regulator of renin angiotensin system (RAS) by converting angiotensin II (Ang II) to angiotensin 1-7. Contrary to this, another RAS component, angiotensin-converting enzyme (ACE) catalyzes synthesis of Ang II from angiotensin I (Ang I) that functions as active compound in blood pressure regulation. This indicates importance of ACE/ACE2 level in regulating blood pressure by targeting Ang II. An outbreak of severe acute respiratory syndrome (SARS) highlighted the additional role of ACE2 as a receptor for SARS coronavirus (SARS-CoV) infection.

Main body of the abstract: ACE2 is a functional receptor for SARS-CoV and SARS-CoV-2. Activation of spike (S)protein by either type II transmembrane serine proteases (TSPS) or cathepsin-mediated cleavage initiates receptor binding and viral entry. In addition to TTSPs, ACE2 can also be trimmed by ADAM 17 (a disintegrin and metalloproteinase 17) that competes for the same receptor. Cleavage by TTSPs activates ACE2 receptor for binding, whereas ADAM17 releases extracellular fragment called soluble ACE2 (SACE2). Structural studies of both ACE2 and S-protein have found critical sites involved in binding mechanism. In addition to studies on structural motifs, few single-nucleotide polymorphism (SNPs) studies have been done to find an association between genetic variants and SARS susceptibility. Though no association was found in those reports, but seeing the non-reproducibility of SNP studies among different ethnic groups, screening of ACE2 SNPs in individual population can be undertaken.

Short conclusion: Thus, screening for novel SNPs focussing on recently identified critical regions of ACE2 can be targeted to monitor susceptibility towards coronavirus disease 2019 (COVID-19).
\end{abstract}

Keywords: Single-nucleotide polymorphism (SNP), ACE2, Severe acute respiratory syndrome (SARS), COVID-19, SARS-CoV-2, Coronavirus

\section{Background}

Angiotensin-converting enzyme (ACE) is a critical component of renin angiotensin system (RAS) that is involved in blood pressure homeostasis [1]. Components of RAS are expressed both systemically and in tissue specific manner [2]. Cleavage of angiotensin I (Ang I) by ACE results in generation of angiotensin II (Ang II) that binds to either angiotensin II type 1 receptor (AT1R) or angiotensin II type 2 receptor (AT2R) [3]. Binding of Ang II to AT1R is mainly involved in blood pressure

Correspondence: mayank.chaudhary@mmumullana.org; mayank.genome@gmail.com

Department of Biotechnology, Maharishi Markandeshwar (Deemed to be University), Mullana, Ambala, Haryana 133207, India regulation. Contrary to this, another homolog of $\mathrm{ACE}$, ACE2 encoded by human X-chromosome can either act on Ang I to give rise to angiotensin 1-9 [4] or on Ang II to generate angiotensin 1-7 [5]. These newly synthesized products from Ang II acts on the Mas receptor that is expressed in tissues related to cardiovascular disease. Binding of Ang II products to Mas receptor can lower blood pressure through vasodilation or through sodium and water excretion in addition to nitric oxide production [6]. In this way, ACE2 negatively regulates ACEAng II signaling effects that primarily cause an increase in blood pressure.

Another major role of ACE2 was highlighted by the emergence of severe acute respiratory syndrome (SARS) 
in 2002-2003 caused by SARS coronavirus (SARS-CoV) $[7,8]$. Human ACE2 acted as functional receptor and binds to spike (S) protein of SARS-CoV with high affinity [9]. Localization of ACE2 protein in various human tissues was explored and was found to be abundantly present in epithelia of lung and intestine, providing a possible route of entry to SARS-CoV [10]. Presence of ACE2 in human airway epithelia was also studied and abundant expression was seen in well-differentiated epithelial cells. In addition to this, predominant expression was seen in apical than the basolateral surface which suggests the availability of enzyme for cleavage of peptides at mucosal surfaces of airway [11]. Similar result was found by $\mathrm{Xu}$ et al. [12] where ACE2 expression was observed on the mucosa of the oral cavity.

Coronaviruses are divided into $\alpha, \beta, \gamma$, and $\delta$ genera on the basis of the target host. Out of these, mammals are infected by $\alpha$ and $\beta-\mathrm{CoV}$ whereas $\gamma$ and $\delta$ - $\mathrm{CoV}$ genera tend to infect birds [13]. A recent respiratory tract infection that has taken the form of pandemic by the name of COVID-19 (coronavirus disease 2019) is found to be caused by SARS-CoV-2 [14]. It is a $\beta-\mathrm{CoV}$ that is enveloped, non-segmented and positive-sense RNA virus [15]. Genome sequencing results showed that this newly discovered virus share $96.2 \%$ identity with bat CoV RaTG13 and $79.5 \%$ identity with SARS-CoV. This data suspected bat to be the natural host and transmission to humans via unknown intermediate host [16]. Recent metagenomic study considered pangolins (Manis javanica) as possible intermediate host that might have acquired the SARS-CoV-2 virus from bats. This consideration was based on putative recombination signals between coronavirus of pangolin, bat, and human [17]. Dependence of this newly discovered virus on the ACE2 receptor to infect humans has again drawn the attention of entire scientific communities towards the binding mechanism of this receptor with viral protein which is considered as a critical step for the entry of the virus. Binding efficiency of S-protein of SARS-CoV-2 with ACE2 was found to be higher than SARS-CoV [18]. Readers interested to know about origin, epidemiology, genome structure, transmission, clinical characteristics, and present medication against SARS-CoV-2 are recommended for Guo et al. [13] as the current article focuses on recent findings within binding sites of ACE2 and SARS-CoV.

Dual functionality of ACE2 as blood pressure regulator and as a receptor for binding of virus particles initiated a debate on the susceptibility of hypertensive individuals against the current pandemic of COVID-19 that are undergoing anti-hypertensive treatment with ACE inhibitors (ACEIs) or angiotensin receptor blockers (ARBs). Different hypothesis have been given (Fig. 1) suggesting the effect of anti-hypertensive medication on viral binding and lung injury [19]. Results in animal models showed upregulation of $A C E 2$ in heart and kidney upon treatment with ACEIs and ARBs [20, 21]. These findings raised concerns on the susceptibility of patients for severity of COVID-19 that are undergoing similar antihypertensive treatment. But studies showing similar effect of ACEIs and ARBs on expression of ACE2 in the lungs are lacking. Moreover, other studies have not reported any such role of ACEIs and ARBs on the expression pattern of $A C E 2[22,23]$. In addition to this, experimental models have suggested that blockade of AT1R though ARBs can reduce Ang II-mediated acute lung injury [24]. Reduction in lung injury can further result in weakening of COVID-19 infection. Therefore, no such human study is available at present which supports the hypothesis that usage of ACEIs and ARBs increases the risk of SARS-CoV-2 infection [19]. This is further supported by the fact that various international societies working on hypertension have recommended continuation of ACEIs and ARBs due to absence of convincing evidence against these medications in present scenario.

\section{Main text \\ ACE2 as functional receptor for SARS-CoV}

ACE2 protein is a transmembrane glycoprotein comprised of 805 amino acids with extracellular catalytic domain, small transmembrane fragment, and short Cterminal cytoplasmic tail [25]. The spike (S) protein of SARS-CoV mediates entry by binding to ACE2 receptor present on cell surface followed by fusion of the viral envelope with host cell membrane [26]. S protein consists of S1 and S2 subunits where S1 subunit is responsible for receptor binding and S2 is responsible for membrane fusion [27]. S1 subunit contains the receptor-binding domain (RBD) at residues 318-510 [28] and S2 harbor elements that are responsible for membrane fusion. Binding of SARS-S protein to ACE2 initiates conformational change in SARS-S that increases proteolytic cleavage of $S$ protein [29]. Activation of spike (S) protein of SARS$\mathrm{CoV}$ involves cleavage by cathepsin [30] or by type II transmembrane serine proteases (TTSPs) that include transmembrane protease serine 2 (TMPRSS2) and human airway trypsin-like protease (HAT) [31]. Both TTSPs are co-expressed with ACE2 in human lung cells [32]. ACE2 can be proteolytically processed by serine proteases (TMPRSS2 and HAT) resulting in SARS-CoV entry or by ADAM17 (a disintegrin and metalloproteinase 17) resulting in the release of extracellular fragment called soluble ACE2 (sACE2) [25, 33]. The role of ADAM17 in the shedding of ACE2 was experimentally proved by modulating ADAM17 expression [34]. Overexpression of ADAM17 increased ACE2 shedding whereas application of natural ADAM inhibitors reduced shedding of ACE2. In 


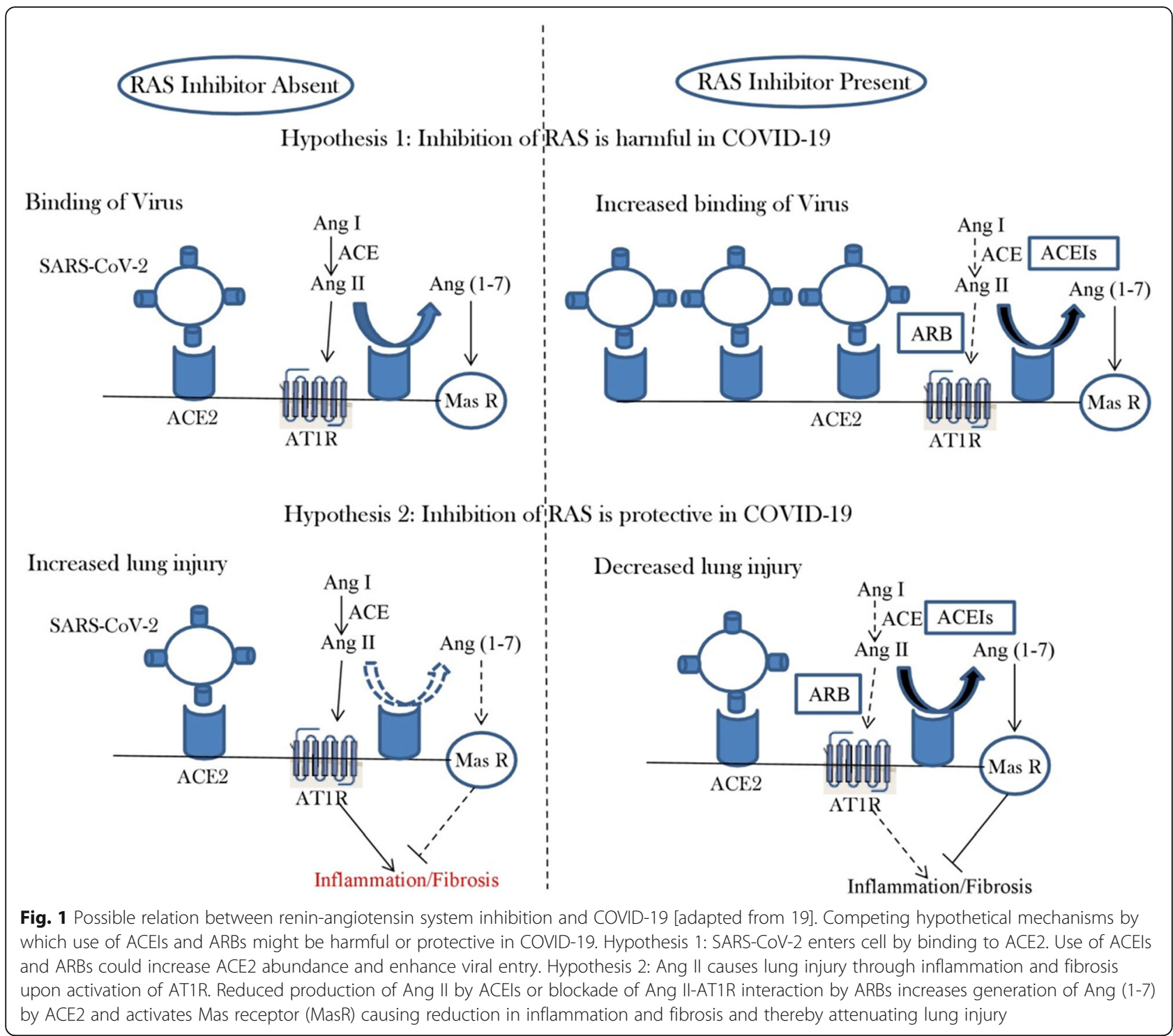

addition to this, both TMPRSS2 and ADAM17 compete for cleavage of ACE2 [35] (Fig. 2) but both these proteases have different cleavage sites. TTSPs dependent proteolysis requires the presence of arginine and lysine residues within 697-716 amino acids, whereas ADAM17 requires the presence of arginine and lysine residues within 652-659 amino acids for cleavage of ACE2. As the observed cleavage site of ADAM17 differed from previous studies [36, 37] so the identified sites were proposed as probable recognition sites for downstream cleavage. Synthesis of sACE2 by ADAM17-mediated processing (Fig. 2) retains its enzymatic activity and can inhibit binding of SARS-S to target cells [36]. These results were in accordance of study done by $\mathrm{Li}$ et al. [9] where the soluble form of ACE2 (sACE2) blocked association between the S1 domain and cultured cells transfected with ACE2. As the binding mechanism of SARS-CoV2 is similar to SARS-CoV so the synthesis of cyclodextrin (CD) and sACE2 complex is suggested as a suitable methodology to block SARS-CoV-2 infection [25]. In addition to this, certain studies have found important regions within receptor binding domain (RBD) of the S1 subunit of SARS-S protein that can be targeted. Deletion of the positively charged region (422-463 amino acids) of RBD affected virus infectivity as an amino acid substitution at targeted sites (R441A) and (R453A) abolished viral entry [38]. Similarly, an important hexapeptide (Tyr-Lys-Tyr-Arg-TyrLeu) at 438-443 amino acids was found in RBD [39]. In addition to structural studies on RBD, significant amino acid residues of ACE2 protein at other sites have also been discovered. The amino acid residues at position 31, 41, 353, 355, and 357 of ACE2 were 


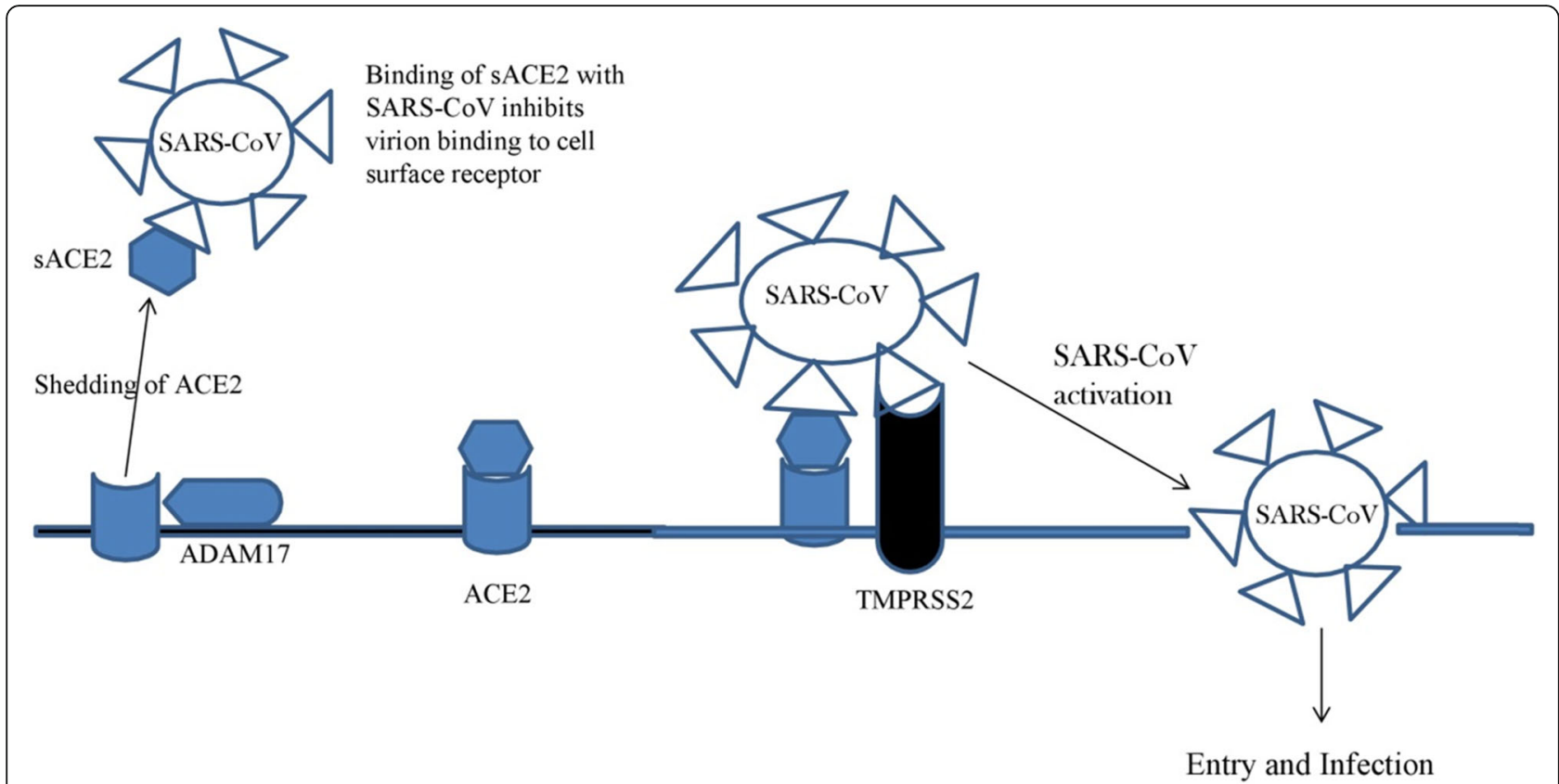

Fig. 2 Action of host cell proteases on ACE2 receptor [adapted from 35]. Cleavage of ACE2 by ADAM17 causes its shedding. Interaction of sACE2 with S-Protein of SARS-CoV prevents binding of virus particles to target cells. Co-expression of TMPRSS2 with ACE2 on target cell surface involves binding of SARS-COV (S-protein) to ACE2- and TMPRSS2-mediated processing allows fusion and uptake of virus particles

found to be significant $[27,40]$ as mutation at these sites strongly inhibited interaction of ACE2 with SARS-S protein. Comparison of rhesus (rh-ACE2) and human (hu-ACE2) yielded non-synonymous substitution and generation of hu-ACE2 (Y217N) mutant caused significant reduction in protein expression and viral entry [41].

\section{Single-nucleotide polymorphisms (SNPs) in ACE2}

Single-nucleotide polymorphism studies have been done in different populations to find association with various diseases. SNPs have been found to affect gene expression resulting in disease outcome. However, these association studies are greatly affected by factors like ethnicity, age, and selection criteria that result in controversial results among different population groups. SNPs of ACE2 have also been studied in different populations to find association with diseases, including essential hypertension, dyslipidemia, hypertrophic cardiomyopathy, ventricular hypertrophy, and cerebral malaria [42-44]. Many of the studied polymorphisms were found to affect ACE2 activity resulting in downregulation of circulating angiotensin (1-7). Association studies targeting ACE2 polymorphisms have reported controversial results in different populations which clearly show the non-reproducibility of association studies. Our literature search targeting $A C E 2$ polymorphisms with severe acute respiratory syndrome resulted in two specific studies $[45,46]$ other than recent reports on COVID-19. Through software based search Chiu et al. [45] identified 103 SNPs in $A C E 2$ which included 2 coding (rs4646116, rs4646179) and 101 intronic SNPs. SNP validation confirmed sequence variation at only 5 non-coding SNP loci (rs2106809, rs2285666, rs4646142, rs714205, rs2074192).

These 5 SNPs were screened in a case-control study involving SARS patients and healthy volunteers, but no statistically significant difference of any of the studied SNPs was found [45]. Thus, no association was found between genetic variants and SARS susceptibility. Similarly, the association of $A C E 2$ SNPs with SARS was studied in Vietnam population where each exon and 5'UTR region was screened for SNPs [46]. This study identified 19 SNPs from which 13 novel and two other SNPs (rs2285666, rs183135788) were screened among collected samples, but no significant difference was found in genotypic and allelic frequencies of these SNPs.

Lack of association of any functional ACE2 polymorphism with SARS infection might be due to lesser number of association studies done previously. Moreover, seeing the possibility of contradictions that arise from such SNP studies among different populations, role of $A C E 2$ variation in susceptibility to SARS infection cannot be ruled out. This hypothesis gets support from a previous study where variation in HIV co-receptor developed resistance to HIV infection in the Caucasian population [47]. Similarly, a recent study has identified four polymorphisms in type II transmembrane protein dipeptidyl peptidase 4 (DPP4) that greatly reduced 
binding and penetration of the middle-east respiratory syndrome coronavirus (MERS-CoV) into target cells [48]. These facts highlight the importance of SNP variation within the identified crucial binding sites [27, 41] and at amino acid residues responsible for either TMPR SS2- or ADAM17-mediated proteolysis of ACE2 [35]. This idea gets support from other studies also where change in key amino acids responsible for interaction is considered crucial for cross-species infections, multihost infection, and differences in disease susceptibility [17]. Screening of these sites along with promoter regions in different populations can result in identification of novel SNPs that might affect susceptibility to SARS infection (Fig. 3). Analysis of the upstream region of $A C E 2$ gene showed the bipartite nature of $A C E 2$ promoter with the presence of two promoter regions separated by an Alu element. These promoters result in distal promoter transcripts (DPT) and proximal promoter transcripts (PPT) that encode same ACE2 protein. Both proximal and distal ACE2 promoter regions possess hepatocyte nuclear factor $1 \alpha$ (HNF1 $\alpha$ ) binding motifs that induce $A C E 2$ expression in pancreatic islets [49]. Thus, both distal and proximal promoter regions should be considered while screening for novel SNPs within ACE2 promoter region.

Results from comparative analysis of ACE2 orthologs among 70 placental mammal species showed $85 \%$ similarity between pangolin and human ACE2. Out of the total variable sites, 30 sites relevant for interaction with SARS-CoV were screened for interspecies variation. Additionally, same sites were also studied for intraspecific variation in humans. These sites were highly conserved within Homo sapiens and showed great variation among placental mammalian species [17]. Recent reports have hypothesized correlation between ACE2 levels and susceptibility to present infection. Higher expression of $A C E 2$ was reported in lungs of men than women. This was related to the severity of the disease in case of males. Moreover, Asian population showed higher ACE2 expression than Caucasian and African American population [50]. Contrary to this, the role of estrogen in upregulation of $A C E 2$ expression and plasma ACE2 activity was suggested as a possible reason for protection of females against COVID-19 infection in comparison to males [33]. Genetic analysis of expression quantitative trait loci (eQTL) and functional coding variants in $A C E 2$

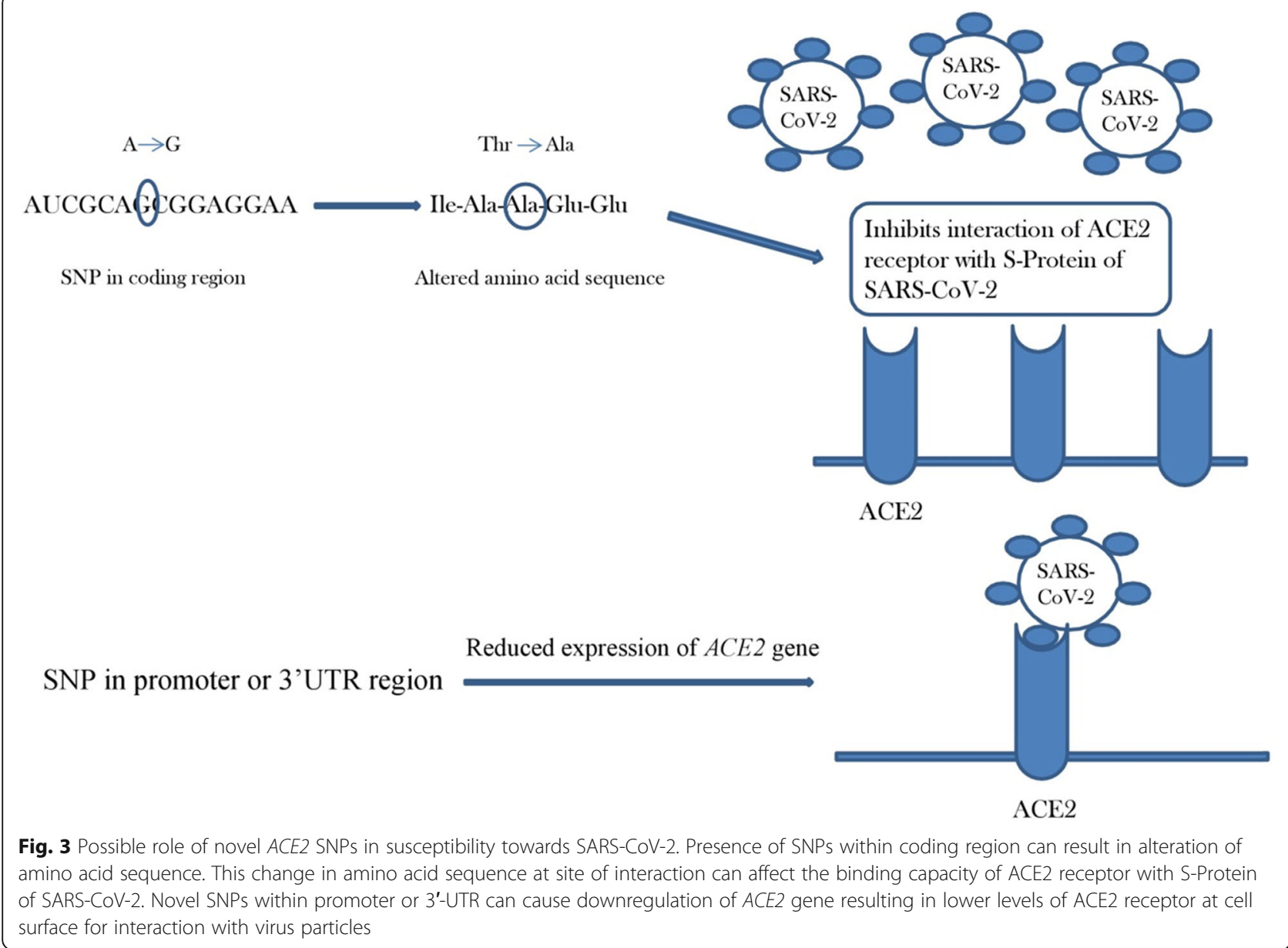


was done to identify mutations resistant to the binding of coronavirus S-protein in different populations [51]. Though no such mutations were identified, but difference in allelic frequencies of certain coding SNPs and eQTL variants were found between Chinese and European population. Higher allelic frequency of certain variants resulted in higher $A C E 2$ expression in Chinese population. These findings highlighted association of $A C E 2$ polymorphism with higher ACE2 expression in East Asian population. Thus, difference in $A C E 2$ expression levels was suggested to cause differential susceptibility for SARS-CoV-2 among different populations under similar conditions. In this context, Wooster et al. [52] identified ACE2 polymorphisms that might influence disease severity. Out of 10 studied SNPs, 5 polymorphisms (rs4240157, rs6632680, rs4830965, rs1476524, and rs2048683) showed an association with higher tissue specific expression of ACE2 resulting in hospitalization whereas rs1548474 polymorphism showed association with low tissue expression and lesser severity. Similarly, variation in circulating ACE2 levels was speculated to be controlled by genetic factors where rs2106809 polymorphism might affect ACE2 levels. CC or CT genotype resulted in greater circulating ACE2 levels when compared with TT genotype. Therefore, quantification of human soluble ACE2 (sACE2) in body fluids was suggested as a protective biomarker for rapid test screening. In addition to a possible link between circulating ACE2 levels and severity of disease, availability of recombinant ACE2 is considered as a hopeful treatment option [33]. Thus, difference in either tissue specific ACE2 expression or plasma ACE2 levels can affect disease severity. This signifies the importance of identifying novel SNPs that can either affect tissue specific ACE2 expression or plasma ACE2 levels. Other studies have also highlighted an association of ACE2 and TMPR SS2 polymorphisms with COVID-19 susceptibility and infection [53, 54]. Additionally, coronavirus infection is related to the state of hypercytokinemia/cytokine storm which is characterized by an excessive synthesis of proinflammatory cytokines resulting in severe outcomes that might include multiple organ damage. Such response of hypercytokinemia was seen in ACE2-positive cells. So, genetic polymorphism in genes responsible for the synthesis of pro-inflammatory cytokines and chemokines along with $A C E 2$ might be responsible for differences in response to COVID-19 [55]. Link between ACE2 levels and immune response can also be related from a study where reduced promoter methylation caused higher expression of $A C E 2$ resulting in immune infiltration of certain tumor cells [56]. As till date, no effective medicine or vaccine is present against COVID-19 so identification of any such functional SNP that can affect population susceptibility will be of great help.

\section{Conclusion}

The role of ACE2 in addition to blood pressure regulation was highlighted from emergence of severe acute respiratory syndrome (SARS) in 2002-2003. Recent outbreak of COVID-19 again highlighted the functional role of ACE 2 as a receptor for the spike (S) protein of SARS-CoV-2 to mediate viral entry. With the availability of no medicine/vaccine at present, the binding potential of ACE2 with $S$ protein along with the role of serine proteases in activation of S protein is vastly explored. In addition to these mechanisms, screening for novel SNPs in recently identified crucial regions of ACE2 can also be targeted for studying susceptibility towards current pandemic.

\section{Abbreviations \\ ACE: Angiotensin-converting enzyme; ACE2: Angiotensin-converting enzyme 2; ACEls: Angiotensin-converting enzyme inhibitors; ADAM17: A disintegrin and metalloproteinase 17; Ang I: Angiotensin I; Ang II: Angiotensin II; ARBs: Angiotensin receptor blockers; AT1R: Angiotensin II type 1 receptor; AT2R: Angiotensin II type 2 receptor; CD: Cyclodextrin; COVID-19: Coronavirus disease 2019; DPP4: Dipeptidyl peptidase 4; DPT: Distal promoter transcripts; eQTL: Expression quantitative trait loci; HAT: Human airway trypsin-like prote- ase; HNF1 a: Hepatocyte nuclear factor 1a; MERS-CoV: Middle-east respiratory syndrome coronavirus; PPT: Proximal promoter transcripts; RAS: Renin angiotensin system; RBD: Receptor-binding domain; S protein: Spike protein; SACE2: Soluble ACE2; SARS: Severe acute respiratory syndrome; SARS- CoV: SARS coronavirus; SNP: Single-nucleotide polymorphism; TMPR SS2: Transmembrane protease serine 2; TTSPs: Type II transmembrane serine proteases}

Acknowledgements

The author is thankful to the institute.

Author's contributions

MC gathered information, compiled and drafted the manuscript. The author read and approved the final manuscript.

Funding

No funding was obtained to draft this review article.

Availability of data and materials

There is no availability of data and materials.

Ethics approval and consent to participate

Not applicable

Consent for publication

Not applicable

\section{Competing interests}

No competing interests

Received: 7 July 2020 Accepted: 9 September 2020

Published online: 21 September 2020

References

1. Skeggs LT, Dorer FE, Levine M, Lentz KE, Kahn JR (1980) The biochemistry of the renin-angiotensin system. Adv Exp Med Biol 130:1-27

2. Lavoie JL, Sigmund CD (2003) Minireview: overview of the renin-angiotensin system-an endocrine and paracrine system. Endocrinology 144(6):2179-2183

3. Dinh DT, Frauman AG, Johnston Cl, Fabiani ME (2001) Angiotensin receptors: distribution, signalling and function. Clin Sci 100(5):481-492

4. Donoghue M, Hsieh F, Baronas E, Godbout K, Gosselin M, Stagliano N et al (2000) A novel angiotensin converting enzyme related corboxypeptidase (ACE2) converts angiotensin I to angiotensin 1-9. Circ Res 87:E1-E9 
5. Tipnis SR, Hooper NM, Hyde R, Karran E, Christie G, Turner AJ (2000) A human homolog of angiotensin converting enzyme. Cloning and functional expression as a captopril-insensitive carboxypeptidase. J Biol Chem 275(43): 33238-33243

6. South AM, Shaltout HA, Washburn LK, Hendricks AS, Diz DI, Chappell MC (2019) Fetal programming and the angiotensin-(1-7) Axis: a review of the experimental and clinical data. Clin Sci 133(1):55-74

7. Drosten C, Gunther S, Preiser W, Van der Werf S, Brodt HR, Becker S et al (2003) Identification of a novel coronavirus in patients with severe acute respiratory syndrome. N Engl J Med 348(20):1967-1976

8. Fouchier RAM, Kuiken T, Schutten M, Van Amerongen G, Van Doornum GJJ, Van der Hoogen BG et al (2003) Aetiology: Koch's postulates fulfilled for SARS virus. Nature. 423(6937):240

9. Li W, Moore MJ, Vasilieva N, Sui J, Wong SK, Berne MA et al (2003) Angiotensin converting enzyme 2 is a functional receptor for the SARS coronavirus. Nature 426(6965):450-454

10. Hamming I, Timens W, Bulthuis MLC, Lely AT, Navis GJ, van Goor H (2004) Tissue distribution of ACE2 protein, the functional receptor for SARS coronavirus. A first step in understanding SARS pathogenesis. J Pathol 203(2):631-637

11. Jia HP, Look DC, Shi L, Hickey M, Pewe L, Netland J et al (2005) ACE2 receptor expression and severe acute respiratory syndrome coronavirus infection depend on differentiation of human airway epithelia. J Virol 79(23): $14614-14621$

12. Xu H, Zhong L, Deng J, Peng J, Dan H, Zeng X, Li T, Chen Q (2020) High expression of ACE2 receptor of 2019-nCoV on the epithelial cells of oral mucosa. Int J Oral Sci 12:8

13. Guo YR, Cao QD, Hong ZS, Tan YY, Chen SD, Jin HJ et al (2020) The origin, transmission and clinical therapies on coronavirus disease 2019 (COVID-19) outbreak-an update on the status. Mil Med Res 7(1):11

14. Lu H, Stratton CW, Tang YW (2020) Outbreak of pneumonia of unknown etiology in Wuhan, China: the mystery and the miracle. J Med Virol 92(4): 401-402

15. Zhu N, Zhang D, Wang W, Li X, Yang B, Song J et al (2020) A novel coronavirus from patients with pneumonia in China, 2019. N Engl J Med 382:727-733

16. Zhou P, Yang XL, Wang XG, Hu B, Zhang L, Zhang W et al (2020) A pneumonia outbreak associated with a new coronavirus of probable bat origin. Nature 579:270-273

17. Fam BSO, Vargas-Pinilla P, Amorim CEG, Sortica VA, Bortolini MC (2020) ACE2 diversity in placental mammals reveals the evolutionary strategy of SARS-CoV-2. Genet Mol Biol 43(2):e20200104

18. Song W, Gui M, Wang X, Xiang Y (2018) Cryo-EM structure of the SARS coronavirus spike glycoprotein in complex with its host cell receptor ACE2. PLoS Pathog 14:e10007236

19. South AM, Tomlinson L, Edmonston D, Hiremath S, Sparks MA (2020) Controversies of renin angiotensin system inhibition during the COVID-19 pandemic. Nat Rev Nephrol 16:305-307

20. Ferrario CM, Jessup J, Chappell MC, Averill DB, Brosnihan KB, Tallant EA et al (2005) Effect of angiotensin converting enzyme inhibition and angiotensin II receptor blockers on cardiac angiotensin converting enzyme 2. Circulation 111:2605-2610

21. Soler MJ, Ye M, Wysocki J, William J, Lloveras J, Batlle D (2009) Localization of ACE2 in the renal vasculature: amplification by angiotensin II type 1 receptor blockade using Telmisartan. Am J Physiol Renal Physiol 296(2): F398-F405

22. Burrell LM, Risvanis J, Kubota E, Dean RG, MacDonald PS, Lu S et al (2005) Myocardial infarction increases ACE2 expression in rat and humans. Eur Heart J 26(4):369-375

23. Ramchand J, Patel SK, Srivastava PM, Farouque O, Burrell LM (2018) Elevated plasma angiotensin converting enzyme 2 activity is an independent predictor of major adverse cardiac events in patients with obstructive coronary artery disease. PLoS One 13(6):e0198144

24. Kuba K, Imai Y, Rao S, Gao H, Guo F, Guan B et al (2005) A crucial role of angiotensin converting enzyme 2 (ACE2) in SARS coronavirus-induced lung injury. Nat Med 11:875-879

25. Sun P, Lu X, Xu C, Wang Y, Sun W, Xi J (2020) CD-sACE2 inclusion compounds: an effective treatment for coronavirus disease 2019 (COVID-19). J Med Virol. https://doi.org/10.1002/jmv.25804

26. Gallagher TM (2001) Buchmeier MJ (2001) coronavirus spike proteins in viral entry and pathogenesis. Virology 279(2):371-374
27. Li W, Zhang C, Sui J, Kuhn JH, Moore MJ, Luo S et al (2005) Receptor and viral determinants of SARS-coronavirus adaptation to human ACE2. EMBO J 24(8):1634-1643

28. Xiao X, Chakraborti S, Dimitrov AS, Grmatikoff K, Dimitrov DS (2003) The SARS-CoV S glycoprotein: expression and functional characterization. Biochem Biophys Res Commun 312(4):1159-1164

29. Li F, Berardi M, Li W, Farzan M, Dormitzer PR, Harrison SC (2006) Conformational states of the severe acute respiratory syndrome coronavirus spike protein ectodomain. J Virol 80(14):6794-6800

30. Simmons G, Gosalia DN, Rennekamp AJ, Reeves JD, Diamond SL, Bates P (2005) Inhibitors of Cathepsin L prevent severe acute respiratory syndrome coronavirus entry. Proc Natl Acad Sci 102(33):11876-11881

31. Matsuyama S, Nagata N, Shirato K, Kawase M, Takeda M, Taguchi F (2010) Efficient activation of the severe acute respiratory syndrome coronavirus spike protein by the transmembrane protease TMPRSS2. J Virol 84(24): 12658-12664

32. Bertram S, Heurich A, Lavender H, Gierer S, Danisch S, Perin P et al (2012) Influenza and SARS coronavirus activating proteases TMPRSS2 and HAT are expressed at multiple sites in human respiratory and gastrointestinal tracts. PLoS One 7:e35876

33. Ciaglia E, Vecchione C, Puca AA (2020) COVID-19 infection and circulating ACE2 levels: protective role in women and children. Front Pediatr 8:206

34. Lambert DW, Yarski M, Warner FJ, Thornhill P, Parkin ET, Smith Al et al (2005) Tumor necrosis factor-alpha convertase (ADAM17) mediates regulated ectodomain shedding of the severe acute respiratory syndrome coronavirus (SARS-CoV) receptor, angiotensin converting enzyme 2 (ACE2). $J$ Biol Chem 280(34):30113-30119

35. Heurich A, Winkler HH, Gierer S, Liepold T, Jahn O, Pohlmann S (2014) TMPR SS2 and ADAM17 cleave ACE2 differentially and only proteolysis by TMPR SS2 augments entry driven by the severe acute respiratory syndrome coronavirus spike protein. J Virol 88(2):1293-1307

36. Jia HP, Look DC, Tan P, Shi L, Hickey M, Gakhar L et al (2009) Ectodomain shedding of angiotensin converting enzyme 2 in human airway epithelia. Am J Physiol Lung Cell Mol Physiol 297(1):L84-L96

37. Lai ZW, Hanchapola I, Steer DL, Smith Al (2011) Angiotensin converting enzyme 2 ectodomain shedding cleavage-site identification: determinants and constraints. Biochemistry 50(23):5182-5194

38. Yi CE, Ba L, Zhang L, Ho DD, Chen Z (2005) Single amino acid substitutions in the severe acute respiratory syndrome coronavirus spike glycoprotein determine viral entry and immunogenicity of a major neutralizing domain. J Virol 79(18):11638-11646

39. Struck AW, Axmann M, Pfefferle S, Drosten C, Meyer B (2012) A hexapeptide of the receptor binding domain of SARS coronavirus spike protein blocks viral entry into host cells via the human receptor ACE2. Antivir Res 94(3): 288-296

40. Towler P, Staker B, Prasad SG, Menon S, Tang J, Parsons T et al (2004) ACE2 $X$-ray structures reveal a large hinge-bending motion important for inhibitor binding and catalysis. J Biol Chem 279:17996-18007

41. Chen Y, Liu L, Wei Q, Zhu H, Jiang H, Tu X, Qin C, Chen Z (2008) Rhesus angiotensin converting enzyme 2 supports entry of severe acute respiratory syndrome coronavirus in chinese macaques. Virology 381(1):89-97

42. Patnaik M, Pati P, Swain SN, Mohapatra MK, Dwibedi B, Kar SK, Ranjit M (2014) Association of angiotensin converting enzyme and angiotensin converting enzyme 2 gene polymorphisms with essential hypertension in the population of Odisha, India. Ann Hum Biol 41(2):145-152

43. Pan Y, Wang T, Li Y, Guan T, Lai Y, Shen Y et al (2018) Association of ACE2 polymorphisms with susceptibility to essential hypertension in dyslipidemia in Xinjiang, China. Lipids Health Dis 17:241

44. Fan Z, Wu G, Yue M, Ye J, Chen Y, Xu B et al (2019) Hypertension and hypertensive left ventricular hypertrophy are associated with ACE2 genetic polymorphism. Life Sci 225:39-45

45. Chiu RWK, Tang NLS, Hui DSC, Chung GTY, Chim SSC, Chan KCA et al (2004) ACE2 gene polymorphisms do not affect outcome of severe acute respiratory syndrome. Clin Chem 50(9):1683-1686

46. Itoyama S, Keicho N, Hijikata M, Quy T, Phi NC, Long HT et al (2005) Identification of an alternative $5^{\prime}$-untranslated exon and new polymorphisms of angiotensin converting enzyme 2 gene: lack of association with SARS in Vietnamese population. Am J Med Genet A 136(1):52-57

47. Samson M, Libert F, Doranz BJ, Rucker J, Liesnard C, Farber CM et al (1996) Resistance to HIV-1 infection in Caucasian individuals bearing mutant alleles of the CCR-5 chemokine receptor gene. Nature 382:722-725 
48. Kleine-Weber H, Schroeder S, Kruger N, Prokscha A, Naim HY, Muller MA et al (2020) Polymorphisms in dipeptidyl peptidase 4 reduce host cell entry of Middle East respiratory syndrome coronavirus. Emerg Microb Infect 9(1):155-168

49. Pedersen KB, Chhabra KH, Nguyen VK, Xia H, Lazartigues E (2013) The transcription factor HNF1a induces expression of angiotensin converting enzyme 2 (ACE2) in pancreatic islets from evolutionarily conserved promoter motifs. Biochim Biophys Acta 1829(11):1225-1235

50. Devaux CA, Rolain JM, Raoult D (2020) ACE2 receptor polymorphism: susceptibility to SARS-CoV-2, hypertension, multi-organ failure and COVID19 disease outcome. J Microbiol Immunol Infect 53(3):425-435

51. Cao Y, Li L, Feng Z, Wan S, Huang P, Sun X et al (2020) Comparative genetic analysis of the novel coronavirus (2019-nCoV/SARS-CoV-2) receptor ACE2 in different populations. Cell Discov 6:11

52. Wooster L, Nicholson CJ, Sigurslid HH, Cardenas CLL, Malhotra R. Polymorphisms in the ACE2 locus associate with severity of COVID-19 infection. medRxiv 2020; doi:10.1101/2020.06.18.20135152.

53. Torre-Fuentes L, Matias-Guiu J, Hernandez-Lorenzo L, Montero-Escribano P, Pytel V, Porta-Etessam J et al (2020) ACE2, TMPRSS2 and Furin variants and SARS-CoV2 infection in Madrid, Spain. J Med Virol. https://doi.org/10.1002/jmv.26319

54. Hou Y, Zhao J, Martin W, Kallianpur A, Chung MK, Jehi L et al (2020) New insights into genetic susceptibility of COVID-19: an ACE2 and TMPRSS2 polymorphism analysis. BMC Med 18(1):216

55. Badawi A (2020) Hypercytokinemia and pathogen-host interaction in COVID-19. J Inflamm Res 13:255-261

56. Yang J, Li H, Hu S, Zhou Y (2020) ACE2 correlated with immune infiltration serves as a prognostic biomarker in endometrial carcinoma and renal papillary cell carcinoma: implication for COVID-19. Aging 12(8):6518-6535

\section{Publisher's Note}

Springer Nature remains neutral with regard to jurisdictional claims in published maps and institutional affiliations.

\section{Submit your manuscript to a SpringerOpen ${ }^{\circ}$ journal and benefit from:}

- Convenient online submission

- Rigorous peer review

- Open access: articles freely available online

High visibility within the field

- Retaining the copyright to your article

Submit your next manuscript at $\boldsymbol{\nabla}$ springeropen.com 